\title{
A global, near real-time system measuring river, lake, and reservoir dynamics
}

\author{
$\underline{\text { J. Hou }}^{\mathrm{a}}$, A. I. J. M. van Dijk ${ }^{\mathrm{a}}$ and H. E. Beck \\ ${ }^{a}$ Fenner School of Environment and Society, The Australian National University, Australian Capital \\ Territory, ${ }^{b}$ Department of Civil and Environmental Engineering, Princeton University, Princeton, New \\ Jersey, USA \\ Email:jiawei.hou@anu.edu.au
}

\begin{abstract}
Measuring and predicting the dynamics of discharge in rivers and water storage in lakes and reservoirs can inform water management and policy decisions, flood management and response, and help understand the influence of climate change and anthropogenic activities on hydrological, biogeochemical, and ecological processes. However, water body dynamics are often poorly observed on the ground. Gauging networks are unevenly distributed and in decline globally, and much gauging data is not publicly accessible in near real-time, if at all. Remote sensing technologies provide a unique alternative to monitor changes in water extent, level and volume in space and time. Our aim was to develop a global monitoring system that provides near real-time river discharge and lake and reservoir storage information from satellite observations. To estimate river discharge, we derived global surface water extent fraction from the 8 -day $0.05^{\circ}$ resolution reflectance data from the Moderate Resolution Imaging Spectroradiometer (MODIS) and used recorded discharge at gauged sites and hydrological model estimates at ungauged sites to train MODIS-based satellite gauging reaches (SGRs) that can be used to estimate river discharge globally. In total, we were able to construct over 2,000 gauge-based and 11,000 model-based SGRs globally (Figure 1). To estimate volume changes in lakes and reservoirs, surface water extent dynamics for over 280 lakes and reservoirs (Figure 1) were derived from a daily 500-m resolution global surface water change dataset. Storage variations were calculated using surface water extent and height time series from the 10-day near real-time global lake and reservoir elevation dataset (G-REALM). As MODIS and G-REALM provide near real-time information, these data similarly allow estimation of river discharge and lake and reservoir storage in near real-time. It is hoped that the global monitoring system provides immediate and relevant information on rivers, lakes, and reservoirs, to inform government, the community and individuals on the current state of water resources in a historical context.
\end{abstract}

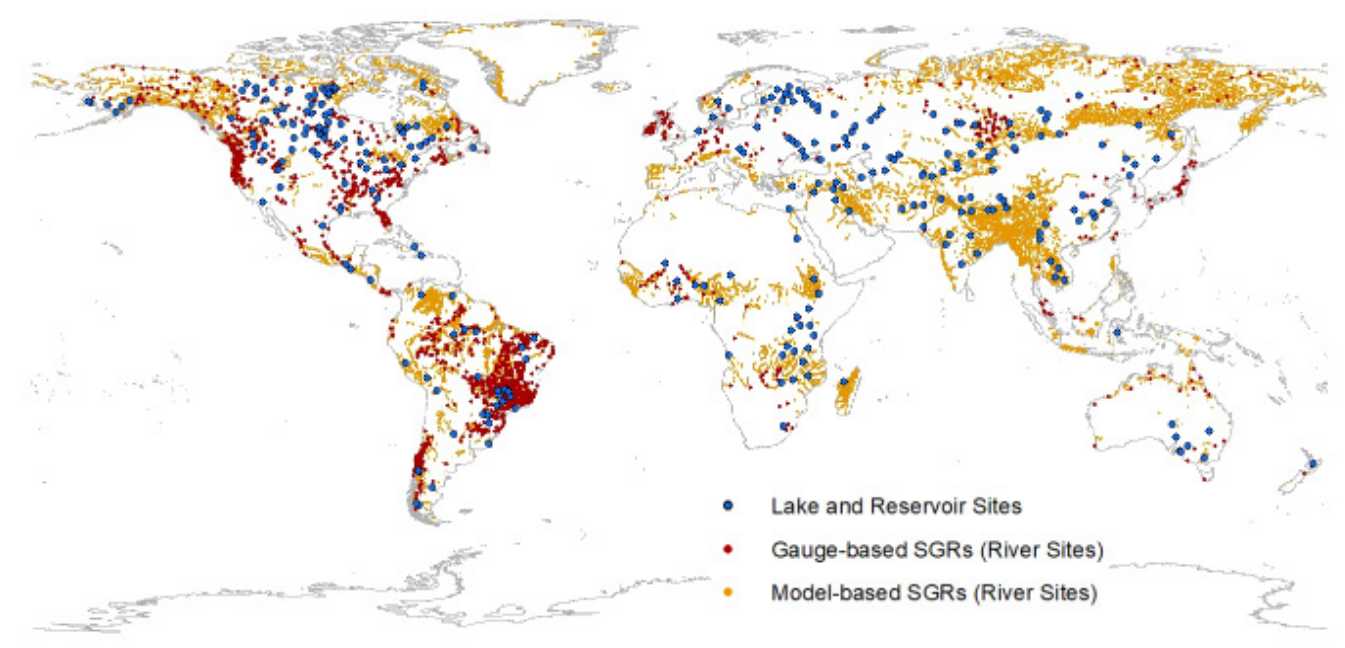

Figure 1. Global distribution of monitoring sites for rivers, lakes and reservoirs.

Keywords: River discharge, lake and reservoir storage, global monitoring system 
Hou et al., A global, near real-time system measuring river, lake, and reservoir dynamics

\section{INTRODUCTION}

Globally, $87 \%$ of the earth's liquid surface freshwater is stored in reservoirs and lakes, and more than $50 \%$ of the potable water supply is extracted either from rivers directly or from reservoirs (Barnett et al. 2005; Gao 2015). According to the statistics on 1.43 million natural lakes and reservoirs with a surface water area greater than $>0.10 \mathrm{~km}^{2}$ from the HydroLAKES and the Global Reservoir and Dam database (GRanD), there are a total of $2.67 \times 10^{6} \mathrm{~km}^{2}$ of natural lakes and $0.26 \times 10^{6} \mathrm{~km}^{2}$ of human-made reservoirs, covering about $2 \%$ of the global land area. The total shoreline length of reservoirs and lakes is approximately four times the global ocean shoreline (Lehner et al. 2011; Messager et al. 2016). Based on the Global River Widths from Landsat (GRWL) database, the total surface area of rivers and streams at mean annual discharge is roughly $7.73 \times 10^{5} \mathrm{~km}^{2}$, which is about $0.58 \%$ of Earth's non-glaciated land surface (Allen and Pavelsky 2018).

With ongoing human interventions and climate change, many rivers, lakes and reservoirs have experienced remarkable changes over the last few decades. Understanding the temporal and spatial dynamics of rivers, lakes and reservoirs at a global scale is essential for a sustainable future. However, variations in surface water dynamics are often poorly observed on the ground. Measurement precision, decline in the number of gauges, disparity in the number of gauges across monitoring networks, economic and technical challenges, limitations in terms of spatial coverage, flood monitoring difficulties, and data intermittency all pose challenges to the use of in-situ data for the analysis of river, lake and reservoir dynamics (Alsdorf et al. 2007; Gao 2015). For example, there are still technical and operational difficulties to produce bathymetric maps of rivers, lakes, or reservoirs, which currently require time- and cost-intensive survey methods (e.g. acoustic profiling). Remote sensing technology provides a unique alternative opportunity to observe changes in water extent, level and volume in space and time, as it is capable of detecting surface water in areas which are inaccessible, remote, or very large, and is unhindered by transboundary issues.

To estimate river discharge from space, the general approach has been to link remote sensing measurement to discharge observed in-situ. Several studies have revealed that river discharge can be estimated based on at-astation hydraulic geometry (AHG) that relates remote sensing derived hydraulic variables to ground measurements of river discharge at a certain reach (e.g. Papa et al. 2010; Pavelsky 2014). In addition, Gleason and Smith (2014) presented a new method, at-many-stations hydraulic geometry, which can be used to estimate discharge solely from remote sensing derived river widths at multiple cross sections, as they found that the parameters of AHG are log-linearly related along a river. River discharge can be also estimated using open-channel hydraulic equations (e.g. the Manning equation) with remotely sensed data and ground measurements of river depth and roughness coefficient (e.g. LeFavour and Alsdorf 2005). Besides, The ratio of wet and dry pixel from Moderate Resolution Imaging Spectroradiometer (MODIS) near-infrared reflectance or the Advanced Microwave Scanning Radiometer (AMSR-E) passive microwave brightness temperature was demonstrated as a readily automated approach to estimate river discharge at large scale (Brakenridge et al. 2007; Hou et al. 2018; Van Dijk et al. 2016).

Lake and reservoir storage variations can be estimated based on the measurements of surface water level and inundation area, either or both of which can be derived from satellite observation. For example, rating curves relating storage, surface water elevation, and inundation area for Lake Izabal (Guatemala) were developed by combining in-situ lake elevation measurements and the ENVISAT Advanced Synthetic Aperture Radar (ASAR) derived inundated areas, and then used to extend volume estimates using the ENVISAT Radar Altimeter (RA-2) data (Medina et al. 2010). Zhang et al. (2014) estimated reservoir storage variations for 21 reservoirs in South Asia using MODIS-derived surface water areas and the ICESat/GLAS altimetry derived surface water elevation measurements. As there are currently several surface water extent and satellite altimetry databases globally, some studies estimated lake and reservoir storage variations derived directly from a combination of these databases (e.g. Busker et al. 2019). To tackle the absence of globally consistent data, Messager et al. (2016) established a geo-statistical model to estimate the volume for lakes with $>0.10$ $\mathrm{km}^{2}$ surface area at global scale, based on their surrounding topography.

The aim of this study was to develop a global monitoring system that can provide near real-time river discharge (2000-current) and lake and reservoir storage variations (1992-current) by combining satellite radar altimetry and optical remote sensing. Here, we present the workflow of our global near real-time monitoring system. We discuss the benefits, limitations, and practical applications of the system. 
Hou et al., A global, near real-time system measuring river, lake, and reservoir dynamics

\section{WORKFLOW}

\subsection{Global river discharge prediction}

Van Dijk et al. (2016) introduced a simple automated statistical method to construct satellite gauging reaches (SGRs) to use in-situ river discharge data to train MODIS optical remote sensing imagery. This is valuable to fill gaps in gauging discharge records and extend river discharge estimates, but the method is limited to gauged river reaches. Hou et al. (2018) expanded the method to both gauged and ungauged reaches using MODIS optical remote sensing and hydrological model simulations. We used the approach developed by Hou et al. (2018) to construct both gauge-based and model-based SGRs at global scale, which can be used to predict river discharge from satellite observation (Figure 2).

The remote sensing data used here to derive river discharge is Moderate Resolution Imaging Spectroradiometer (MODIS) product MCD43C4 version 6, which produces 8-day Nadir BRDF (Bidirectional Reflectance Distribution Function)-Adjusted Reflectance (NBAR) data derived from NASA's Terra and Aqua MODIS instruments. This product provides global $0.05^{\circ} \times 0.05^{\circ}$ resolution imagery from 2000 to present in near real-time. The MCD43C4's shortwave infrared (SWIR) band 7 (2105-2155 nm) was chosen due to the contrast between water and dry land in this wavelength. A surface water extent fraction $(w)$ for each grid cell of each imagery was estimated as follows:

$\mathrm{W}=\frac{\rho_{M}-\rho_{d r y}}{\rho_{\text {water }}-\rho_{d r y}}$

where $\rho_{M}$ is the band 7 reflectance of target cell $M, \rho_{d r y}$ is the fifth percentile highest reflectance in a $7 \times 7$ cell window around $\mathrm{M}$, and $\rho_{\text {water }}$ is the reflectance of surface water (assumed equal to 0.008; refer to Van Dijk et al., 2016 for further details).

Daily and monthly in-situ river discharge observations were collated from different national and international sources (i.e., the United States Geological Survey, the Global Runoff Data Centre, the Brazilian Agência Nacional de Águas, the European Environment Agency, the Water Survey of Canada, the Australian Bureau of Meteorology, the Chilean Center for Climate and Resilience Research, and the National Center for Atmospheric Research). In total, this yielded 22,808 gauging records. For ungauged river reaches, daily river discharge for the period 2000-2014 was simulated by the World-Wide Water model (W3) version 2, which is a $0.05^{\circ} \times 0.05^{\circ}$ grid-based, one-dimensional water balance model that has a semi-distributed representation of the surface water, soil, groundwater stores and is coupled to a grid-based routing scheme (Van Dijk et al. 2018).

We constructed over 2,000 gauge-based and 11,000 model-based SGRs globally, which are able to predict river discharges with Pearson correlations above 0.6 against in-situ or modeling data. For each site, a search window of $0.55^{\circ} \times 0.55^{\circ}$ centers on a gauging station (gauge-based SGRs) or W3 model grid cell with a river flowing through it (model-based SGRs). Observed or modelled discharge time series for the target reach are compared with each MODIS-derived surface water extent fraction time series within the search window. The MODIS pixel that has the strongest correlation with discharge data is selected as the best pixel to reflect river discharge variations. The relationship (QW) between discharge and water extent time series is

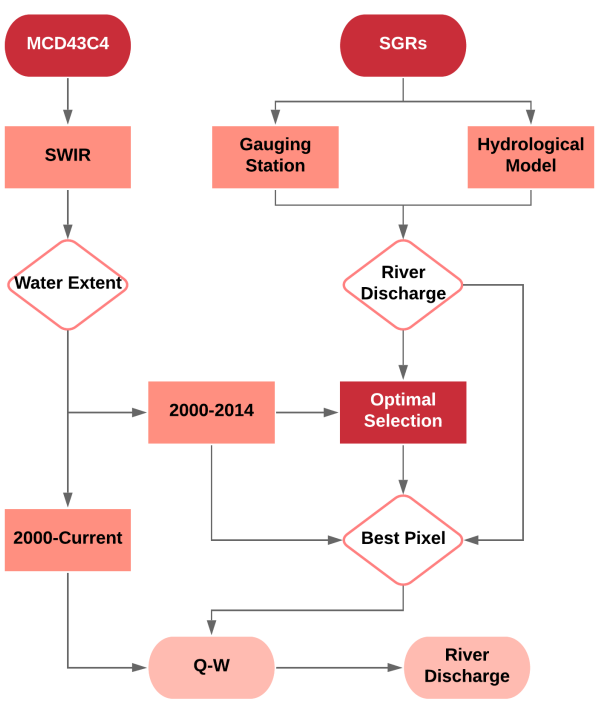

Figure 2. Workflow of river discharge prediction through satellite observation. established for the years 2000-2014 using cumulative distribution function (CDF) matching; river discharge is then predicted based on the developed relationship (Q-W) using MODIS-derived surface water extent fraction time series for the years 2000-present for filling the gaps in gauging data and providing near real-time data (Figure 2). 
Hou et al., A global, near real-time system measuring river, lake, and reservoir dynamics

\subsection{Global lake and reservoir storage measurement}

Sufficiently high-resolution remote sensing is needed to measure lake and reservoir volume variations. A $500-\mathrm{m}$ resolution global surface water change dataset ( $\mathrm{Ji}$ et al. 2018) was used in this study. It provides daily surface water mapping derived from MODIS surface reflectance product, MOD09GA version 6, for the period of 2001 to 2016. The product achieved accuracy of over 93\% compared with classification results derived from Landsat. In addition, the U.S. Department of Agriculture's Foreign Agricultural Service (USDA-FAS) 10-day near real-time global lake and reservoir elevation dataset (G-REALM) was used. This surface water height product for more than 290 lakes and reservoirs around the world was produced by a semi-automated process developed by the NASA Ocean Altimeter Pathfinder Project, using near real-time data from the Jason-3 mission (2016-current) and archive data from the Topex/Poseidon (1992-2008), Jason1 (2002-2008), and Jason-2 (2008-2016) missions. The accuracy is expected to better than $10 \mathrm{~cm}$ root-meansquare (rms) error for the largest water bodies (e.g. Lake Victoria, Africa), and better than $20 \mathrm{~cm} \mathrm{rms}$ for smaller ones (e.g. Lake Chad, Africa).

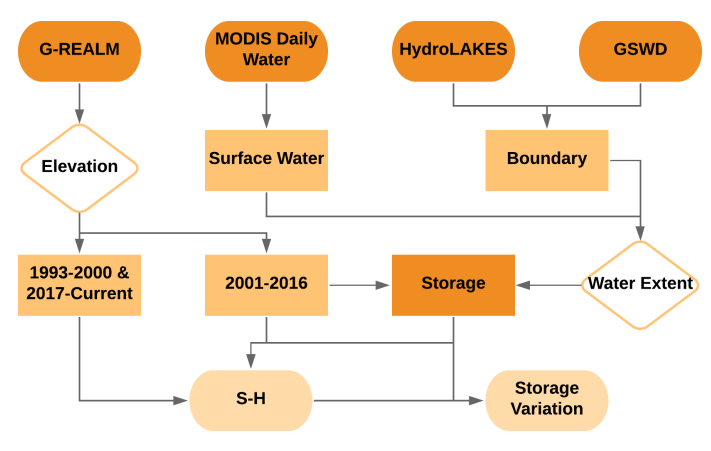

Figure 3. Workflow of lake and reservoir storage measurement from satellite observations.

For each lake or reservoir, we selected surface water images from one MODIS tile or combined tiles, depending on the size of water body, of the 500-m resolution global surface water change dataset ( $\mathrm{Ji}$ et al. 2018) at the dates with surface water height records between 2001 and 2016. The maximum boundary for each lake or reservoir was delineated based on the HydroLAKES database (Messager et al. 2016), which provides the shoreline polygons of lakes and reservoirs with surface extent above $>0.10$ $\mathrm{km}^{2}$, and the maximum surface water product from the Global Surface Water Dataset (GSWD) of the European Commission Joint Research Centre (Pekel et al. 2016). The lake or reservoir surface water extent was derived for all selected surface water images within the maximum boundary. Lake and reservoir storage variations for 2001-2016 were calculated using surface water height records and surface water extents as follows:

$\Delta \mathrm{S}=\Delta h \times\left(A_{1}+A_{2}\right) / 2$

where $\Delta S$ is the change of storage from time 1 to time $2, \Delta h$ is the surface water height variation with respect to the average height, $A_{1}$ is the surface water area at time 1 , and $A_{2}$ is the surface water area at time 2 . The (S-H) relationship, between surface water height records and calculated storage variations, was established for all lakes and reservoirs using data for 2001-2016. Next, storage variations for 1992-2000 and 2017-current were estimated based on the developed (S-H) relationship and combined with estimates for 2001-2016 (Figure 3).

\subsection{The operation of the global near real-time monitoring system}

The SGRs-derived historical river discharge $\left(Q_{h}\right)$ and the $(\mathrm{Q}-\mathrm{W})$ relationship between discharge and water extent for each SGRs site were stored on the National Computational Infrastructure (NCI), in Australia. The NCI also provides a copy of the MODIS MCD43C4 version 6 imagery required that is kept updated with the NASA Land Processes Distributed Active Archive Center (LP DAAC) Distribution Server at the USGS Earth Resources Observation and Science (EROS) Center (https://e4ft101.cr.usgs.gov/MOTA/MCD43C4.006/).

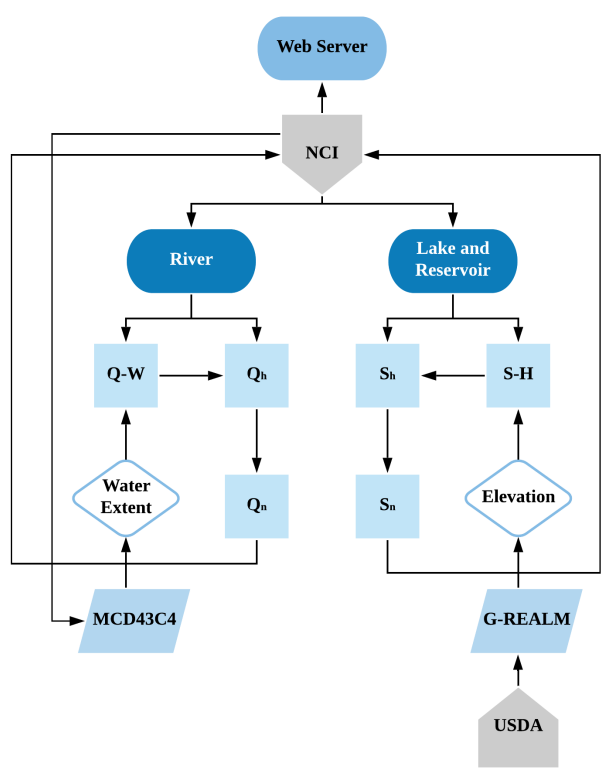

Figure 4. The overall workflow of the global near real-time monitoring system. 
Hou et al., A global, near real-time system measuring river, lake, and reservoir dynamics

Therefore, we are able to derive up to date surface water extent fraction data from the updated MCD43C4 imagery on NCI directly. Next, the near real-time river discharge is calculated from water extent based on the developed (Q-W) relationship. Finally, the updated river discharge time series $\left(Q_{n}\right)$ are stored on NCI. Similar to river discharge, storage variation time series $\left(S_{h}\right)$ and the $(\mathrm{S}-\mathrm{H})$ relationship for each lake and reservoir are stored. The updated surface water elevations are retrieved from the USDA's web server. Next, the up-to-date volume changes are derived from the new surface water height observations based on the (SH) relationship and the new storage variations $\left(S_{n}\right)$ are stored (Figure 4). All data used and produced are stored on the Australian National Computational Infrastructure (NCI) and exposed via THREDDS web services.

All dynamic river discharge and lake and reservoir storage information is displayed online through a web application using the NCI web services. The statistics for rivers are also provided, including real-time streamflow compared to historical streamflow for the time of year, the river discharge hydrograph showing different flood return periods, and recent river discharge plotted over the long-term statistics of discharge for each day of the year. River morphology data (e.g. Hou et al. 2019) may also present useful information that can be assigned to each river reach and may be added in future.

\section{DISCUSSION AND CONCLUSION}

This study presents the workflow of a global monitoring system that measures river discharge and lake and reservoir storage variations from satellite observations in near real-time. The algorithm developed by Hou et al. 2018 was used here to predict river discharge, and we extended this approach to a global application and made the best use of the near real-time merit of MCD43C product. The global surface water change dataset (Ji et al., 2018) and G-REALM surface water height product provide basic elements to measure lake and reservoir storages, and G-REALM product makes it possible to both reproduce historical storage records back to 1992 and provide valuable near real-time information. Errors in forcing data (e.g., precipitation, radiation, temperature), a lack of model parameter optimization or model structural deficiencies from the hydrological model can propagate to model-based SGRs. But some model-based SGRs did outperform the model itself, which provide opportunities to improve model estimates through assimilation of SGR discharge estimates. Wide channels and broad floodplains provide the best conditions for SGRs, and lake and reservoir storage measurement targets at water bodies with water extent above $100 \mathrm{~km}^{2}$, limited by G-REALM product. Higher temporal and spatial input remote sensing data could enhance the capabilities of the monitoring system to observe more rivers, lakes, and reservoirs and to improve the accuracy of the measurements.

Surface water area can also be measured with alternative passive and active satellite sensors, which could be incorporated into the monitoring system. Active microwave sensors (e.g. synthetic aperture radar) are able to observe water regardless of cloud and vegetation cover, but can require complex image processing that is currently not easily automated (Gao, 2015). Passive microwave sensors (e.g., AMSR-E, AMSR2, SMAP) can be used to estimate inundation extent, but their spatial resolution is too coarse to detect narrow or small water bodies, including many rivers, lakes and reservoirs. The most common way to estimate the surface water area of rivers, lakes and reservoirs at global scale has been to use passive visible/infrared bands of satellite sensors such as MODIS and Landsat. The main advantage of MODIS (2000-current) is that it provides daily observations with medium spatial resolution $(250 \mathrm{~m}$ or $500 \mathrm{~m})$ that are readily available from NASA. Similar observations are available from Sentinel-3 and VIIRS. Landsat (1972-current) provides a higher spatial resolution (ca. $30 \mathrm{~m}$ ) but is available with much lower frequency (i.e. 16 days). Both are affected by cloud contamination. The Sentinel-2A and B instruments provide potential to improve revisit time for most of the world to 5 days or better with a spatial resolution of 10-60 m. However, they were launched in or after 2015 , and hence currently only cover a relatively short period of observation.

There are several satellite radar altimeters commonly used to estimate surface water elevation of large inland water bodies at global scale. These satellites include GEOSAT (1985-1989), Topex/Poseidon (1992-2002), ERS-1 and 2 (1992-2003), GFO (2000-2008), ENVISAT (2002-2010), Jason-1, 2 and 3 (2002-current), and Sentinel-3A and B (2016-current). Their return period ranges from 10 to 35 days. The main limitations of radar altimeters are their low spatial resolution and the influence of the target's surrounding topography (Gao, 2015). In contrast, satellite laser altimeters (e.g. ICESat) are able to measure elevation of water bodies even at smaller sizes or in mountainous regions, as they have higher spatial resolution and smaller cross track spacing (Zhang, et al., 2014). However, they have quite a long return period (e.g. 91 days for ICESat), which makes them unsuitable for operational monitoring. There are other satellite altimetry databases, including the Database for Hydrological Time Series of Inland Waters (DAHITI), the European Space Agency's (ESA) River and Lake data set and the French Space Agency Centre National d'Etudes Spatiales' (CNES) 
Hou et al., A global, near real-time system measuring river, lake, and reservoir dynamics

Hydrology by Altimetry. These datasets, as well as available near real-time in-situ water level records (e.g. from the United State Army Corps of Engineers and the United States Geological Survey) could also be implemented in this global monitoring system and this will be the focus of future research.

Long-term records are the basis for designing flood control, irrigation and hydropower systems, and transboundary water agreements, while real-time data are needed to operate water infrastructure, and manage and reduce flood and drought risk (García et al. 2016; Sheffield et al. 2018). They are valuable to make better connections between researchers, policy-makers, and the society for a deeper understanding of the changes that are occurring in our environment due to climate change and anthropogenic activities. Our goal was to contribute global, near real-time information on river, lake and reservoir dynamics to make it easier for government, the community and individuals to access current information on the state of water resources in their region of interest and in a historical context.

\section{ACKNOWLEDGMENTS}

We thank the NASA, USGS and USDA for providing the MODIS products and the global lake/reservoir surface water height data. The first author thanks the ANU-CSC (the Australian National University and the China Scholarship Council) Scholarship for supporting his $\mathrm{PhD}$ study at the Australian National University. Calculations were performed on the high-performance computing system, Raijin, from the National Computational Infrastructure (NCI), which is supported by the Australian Government.

\section{REFERENCES}

Allen, G.H., \& Pavelsky, T.M. (2018). Global extent of rivers and streams. Science, 361, 585-588

Alsdorf, D.E., Rodriguez, E., \& Lettenmaier, D.P. (2007). Measuring surface water from space. Reviews of Geophysics, 45

Barnett, T.P., Adam, J.C., \& Lettenmaier, D.P. (2005). Potential impacts of a warming climate on water availability in snow-dominated regions. Nature, 438, 303

Brakenridge, G.R., Nghiem, S.V., Anderson, E., \& Mic, R. (2007). Orbital microwave measurement of river discharge and ice status. Water Resources Research, 43

Busker, T., de Roo, A., Gelati, E., Schwatke, C., Adamovic, M., Bisselink, B., Pekel, J.-F., \& Cottam, A. (2019). A global lake and reservoir volume analysis using a surface water dataset and satellite altimetry. Hydrology and Earth System Sciences, 23, 669-690

Gao, H. (2015). Satellite remote sensing of large lakes and reservoirs: From elevation and area to storage. Wiley Interdisciplinary Reviews: Water, 2, 147-157

García, L.E., Rodríguez, D.J., Wijnen, M., \& Pakulski, I. (2016). Earth observation for water resources management: Current use and future opportunities for the water sector. Washington, DC: World Bank Group.

Gleason, C.J., \& Smith, L.C. (2014). Toward global mapping of river discharge using satellite images and atmany-stations hydraulic geometry. Proceedings of the National Academy of Sciences, 111, 4788-4791

Hou, J., Van Dijk, A.I.J.M., Renzullo, L.J., \& Vertessy, R.A. (2018). Using modelled discharge to develop satellite-based river gauging: a case study for the Amazon Basin. Hydrology and Earth System Science, 22, 6435-6448

Hou, J., Van Dijk, A.I.J.M., Renzullo, L.J., Vertessy, R.A., \& Mueller, N. (2019). Hydromorphological attributes for all Australian river reaches derived from Landsat dynamic inundation remote sensing. Earth System Science Data, 11, 1003-1015

Ji, L., Gong, P., Wang, J., Shi, J., \& Zhu, Z. (2018). Construction of the 500 - m Resolution Daily Global Surface Water Change Database (2001 - 2016). Water Resources Research, 54, 10,270-210,292

LeFavour, G., \& Alsdorf, D. (2005). Water slope and discharge in the Amazon River estimated using the shuttle radar topography mission digital elevation model. Geophysical Research Letters, 32

Lehner, B., Liermann, C.R., Revenga, C., Vörösmarty, C., Fekete, B., Crouzet, P., Döll, P., Endejan, M., Frenken, K., \& Magome, J. (2011). High - resolution mapping of the world's reservoirs and dams for sustainable river - flow management. Frontiers in Ecology and the Environment, 9, 494-502

Medina, C., Gomez-Enri, J., Alonso, J.J., \& Villares, P. (2010). Water volume variations in Lake Izabal (Guatemala) from in situ measurements and ENVISAT Radar Altimeter (RA-2) and Advanced Synthetic Aperture Radar (ASAR) data products. Journal of Hydrology, 382, 34-48

Messager, M.L., Lehner, B., Grill, G., Nedeva, I., \& Schmitt, O. (2016). Estimating the volume and age of water stored in global lakes using a geo-statistical approach. Nature communications, 7, 13603 
Hou et al., A global, near real-time system measuring river, lake, and reservoir dynamics

Papa, F., Durand, F., Rossow, W.B., Rahman, A., \& Bala, S.K. (2010). Satellite altimeter - derived monthly discharge of the Ganga - Brahmaputra River and its seasonal to interannual variations from 1993 to 2008. Journal of Geophysical Research: Oceans, 115

Pavelsky, T.M. (2014). Using width - based rating curves from spatially discontinuous satellite imagery to monitor river discharge. Hydrological Processes, 28, 3035-3040

Pekel, J.-F., Cottam, A., Gorelick, N., \& Belward, A.S. (2016). High-resolution mapping of global surface water and its long-term changes. Nature, 540, 418-422

Sheffield, J., Wood, E.F., Pan, M., Beck, H., Coccia, G., Serrat - Capdevila, A., \& Verbist, K. (2018). Satellite remote sensing for water resources management: potential for supporting sustainable development in data-poor regions. Water Resources Research, 54, 9724-9758

Van Dijk, A.I.J.M., Brakenridge, G.R., Kettner, A.J., Beck, H.E., De Groeve, T., \& Schellekens, J. (2016). River gauging at global scale using optical and passive microwave remote sensing. Water Resources Research, 52, 6404-6418

Van Dijk, A.I.J.M., Schellekens, J., Yebra, M., Beck, H.E., Renzullo, L.J., Weerts, A., \& Donchyts, G. (2018). Global $5 \mathrm{~km}$ resolution estimates of secondary evaporation including irrigation through satellite data assimilation. Hydrology and Earth System Science, 22, 4959-4980

Zhang, S., Gao, H., \& Naz, B.S. (2014). Monitoring reservoir storage in South Asia from multisatellite remote sensing. Water Resources Research, 50, 8927-8943 